\title{
Determination of the critical points in solid-state phase transformation of some hypoeutectoid steels
}

\author{
Constantin Dulucheanu ${ }^{1}$,Traian Lucian Severin ${ }^{1}$, Alexandru Potorac ${ }^{1}$ and Luminita Irimescu ${ }^{1}$ \\ ${ }^{1}$ Faculty of Mechanical Engineering, Mechatronics and Management \& Research Center MANSiD, University "Stefan cel Mare" of \\ Suceava, 13 Universitatii Street, 720229 Suceava, Romania
}

\begin{abstract}
This study allowed, by dilatometric analyses, both to highlight the solid state transformations that occurred during the continuous heating of two hypoeutectoid steels, as well as to investigate the effect of the heating rate on the critical points at which these transformations occurred. The eutectoid transformation (the pearlite dissolution into austenite) was carried out in a temperatures interval, ranging between pearlite dissolution start temperature $\left(A c_{l}\right)$ and pearlite dissolution finish temperature (denoted $A c_{f p}$ in this article). Increasing the heating rate determined a displacement of the critical points in solid-state phase transformation to higher temperatures; these displacements were more significant for the $A c_{f p}$ point, than for the critical points $A c_{l}$ and $A c_{3}$.
\end{abstract}

\section{Introduction}

In commercial steels, in industrial heating conditions, the pearlite dissolution into austenite (eutectoid transformation, $\mathrm{P} \rightarrow \mathrm{A})$ no longer occurs at constant temperature, but in a temperatures range, namely, between pearlite dissolution start temperature $\left(A c_{l}\right.$ critical point) and pearlite dissolution finish temperature (denoted $A c_{f p}$ in this article). The temperature $A c_{f p}$ indicates the beginning of ferrite and austenite coexistence range during heating (beginning of the allotropic transformation of ferrite into austenite, $\mathrm{F} \rightarrow \mathrm{A}$ ), range that stretches up to the temperature of the $A c_{3}$ point. The determination of the temperatures range $\left(A c_{f p}-A c_{3}\right)$ is of great importance for the dual-phase steels production technologies [1-6]. These steels have a low carbon content and a structure formed of a soft and ductile ferrite matrix in which are homogeneously dispersed, martensite (10 to $35 \%$ ) and a small amount of residual austenite ( 1 to $2 \%$ ) [4, 8-12]. The main technology for producing such steels consists of the intercritical quenching. The structure obtained, for a given chemical composition, is the result of combined action of the technological parameters of intercritical heat treatment (heating temperature, heating rate, cooling rate etc.), their influence on the structure of the material being directly reflected on its properties. Consequently, for designing and developing a dual-phase steel production technology, it is necessary to know both the temperatures of the critical points $A c_{1}, A c_{f p}$ and $A c_{3}$, as well as the influence of certain technological parameters (heating rate, grain size of ferrite and austenite etc.) on these points. A quick and convenient method for determining the temperature of critical points in solid-state phase transformation when heating a steel lies in the use of mathematical models that take into account the chemical composition (equations obtained by statistical processing of experimental results), but these equations can generate large errors [2-4, 13]. A high precision in determining these temperatures is obtained by dilatometric analyses; modern dilatometers, conected to computerised systems, collect the signals of change in the length of a specimen as a function of temperature, plot a dilatometric curve, $\Delta \mathrm{L} / \mathrm{L}_{\mathrm{o}}=\mathrm{f}(\mathrm{T})$, calculate and generate its corresponding derivative, $\mathrm{d}\left(\Delta \mathrm{L} / \mathrm{L}_{\mathrm{o}}\right) / \mathrm{dT}=\mathrm{f}(\mathrm{T})$, and allow the identification of both critical points $A c_{1}$ and $A c_{3}$, as well as the pearlite dissolution finish temperature (the $A c_{f p}$ point)and therefore, the determination of the temperatures range $\left(A c_{f p}-A c_{3}\right)[3,4,6,14,15]$. Unfortunately, the literature is relatively poor in information on the results of dilatometric analyses performed in order to identify the temperatures of the critical points in solid-state phase transformation of dual-phase steels or to establish the influence of some technological parameters (heating speed, initial structure, grain size etc.) on these critical temperatures. At the moment, in the world, numerous research are carried out in order to obtain and characterize some dual-phase steels with different chemical compositions, to be used also in other fields than the automotive industry (civil buildings, oil industry, naval industry etc.). However, in most scientific articles presenting the results of these researches, the authors do not indicate the temperatures of the critical points or do they mention that they have estimated these temperatures using mathematical models.

This article describes some of the researches carried out at University "Stefan cel Mare" of Suceava, Romania, in order to obtain and characterise dual-phase steels; the 
results of the dilatometric analyzes performed on specimens made from two of the alloys used in the research are presented. As a result of these researches, the temperatures of the critical points in solid-state phase transformation were identified and the influence of the heating rate on these temperatures was established.

\section{Experimental details}

The chemical compositions of the investigated two $\mathrm{Fe}-\mathrm{C}$ alloys (denoted A_Steel and B_Steel in this article) were determined with a FOUNDRY-MASTER Xpert spectrometer (Oxford Instruments Analytical $\mathrm{GmbH}$, Germania); they are shown in Table 1.

Table 1. The chemical compositions of the alloys.

\begin{tabular}{|c|c|c|c|c|c|}
\hline Alloy & \multicolumn{5}{|c|}{ Chemical composition (wt. \%) } \\
\hline \multirow{5}{*}{ A_Steel } & $\mathrm{C}$ & $\mathrm{Mn}$ & $\mathrm{Si}$ & $\mathrm{P}$ & $\mathrm{S}$ \\
& 0.087 & 0.511 & 0.091 & 0.0036 & 0.0039 \\
\cline { 2 - 6 } & $\mathrm{Cr}$ & $\mathrm{Mo}$ & $\mathrm{Ni}$ & $\mathrm{Al}$ & $\mathrm{Cu}$ \\
& 0.029 & 0.005 & 0.049 & 0.003 & 0.082 \\
\cline { 2 - 6 } & $\mathrm{V}$ & $\mathrm{W}$ & $\mathrm{Fe}$ & - & - \\
\hline \multirow{5}{*}{ B_Steel } & 0.003 & 0.003 & balance & & \\
\hline & $\mathrm{C}$ & $\mathrm{Mn}$ & $\mathrm{Si}$ & $\mathrm{P}$ & $\mathrm{S}$ \\
& 0.093 & 1.922 & 0.065 & 0.0191 & 0.0116 \\
\cline { 2 - 6 } & $\mathrm{Cr}$ & $\mathrm{Mo}$ & $\mathrm{Ni}$ & $\mathrm{Al}$ & $\mathrm{Cu}$ \\
& 0.111 & 0.036 & 0.092 & 0.012 & 0.154 \\
\cline { 2 - 6 } & $\mathrm{Fe}$ & - & - & - & - \\
\hline & balance & - & & & \\
\hline
\end{tabular}

These alloys are commercial steels, produced and used in industry, mainly, for electrodes and welding wires. Their initial structures were ferrite-pearlite, consisting of $85.30 \%$ ferrite and $14.70 \%$ pearlite for A_Steel and $73.80 \%$ ferrite and $26.20 \%$ pearlite for B_Steel.

The dilatometric analyses were made with a DIL 402 Expedis-SUPREME Dilatometer (NETZSCH Gerätebau $\mathrm{GmbH}$, Germany), on cylindrical specimens with a diameter of $5 \mathrm{~mm}$ and a length of $25 \mathrm{~mm}$, continuous heated in $(30 \div 980){ }^{\circ} \mathrm{C}$ temperature range, in nitrogen atmosphere $\left(100 \mathrm{ml} / \mathrm{min} \mathrm{N}_{2}\right)$ and with a load at the specimen of $200 \mathrm{mN}$. The researches carried out also aimed to establish the influence of the heating rate on the critical points in solid-state phase transformation of the two steels. Therefore, the dilatometric analyses were performed with the following heating rates: 1, 3, 5, 10 și $30 \mathrm{C} / \mathrm{min}$; for each heating rate, three analyses were made (three specimens for each heating rate). Finally, the signals provided by the dilatometer were processed with NETZSCH Proteus ${ }^{\circledR}$ Software 7.1.0.

\section{Results and discussion}

The signals of change in the length of the specimens as a function of temperature, collected during dilatometric analyses with the computerised systems of the DIL 402 Expedis-SUPREME Dilatometer, have led to the plotting of the dilatometric curves, as well as to the calculation and graphic representation of their derivatives. Figures 1 and 2 show the dilatometric curves and their corresponding derivatives of A_Steel and B_Steel (for the heating rate of $3^{\circ} \mathrm{C} / \mathrm{min}$ ).

Normally, nodifference between the pearlite dissolution process $(\mathrm{P} \rightarrow \mathrm{A})$ and the allotropic transformation of ferrite into austenite $(\mathrm{F} \rightarrow \mathrm{A})$ is detected on the continuous heating dilatometric curve obtained for a hypoeutectoid $\mathrm{Fe}-\mathrm{C}$ binary alloy $[4,5]$; however, all the dilatometric curves drawn for the A_Steel and B_Steel (regardless of the heating rate) present an unusual anomaly at the onset of the austenitization. This obvious anomaly, highlighted by other researchers as well [1, 3-7, 14-16], is a contraction associated to the pearlite dissolution (Figures 1 and 2).

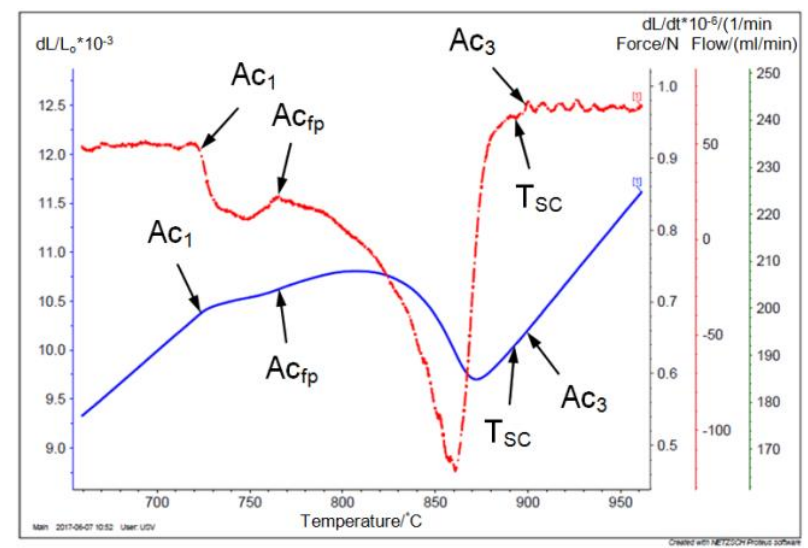

Figure 1. Dilatometric curve (continuous line) and its corresponding derivative (dashedline) of the A_Steel, for the heatingrate of $3{ }^{\circ} \mathrm{C} / \mathrm{min}$.

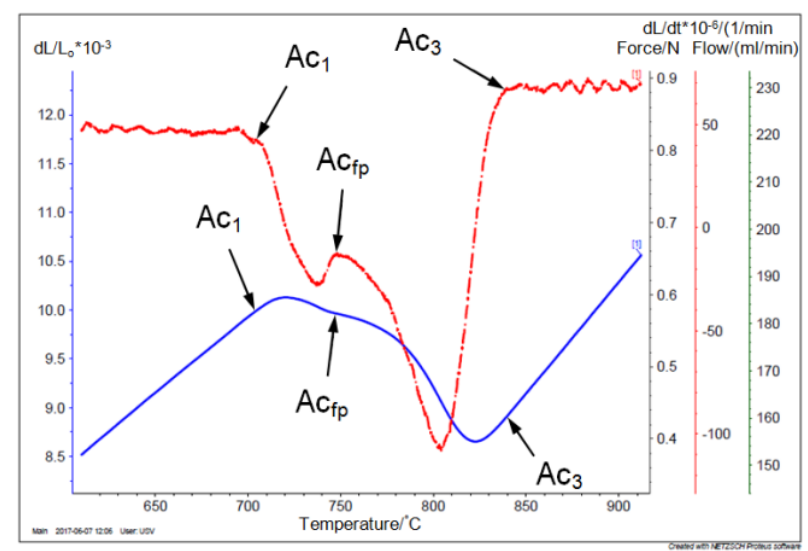

Figure 2. Dilatometric curve (continuous line) and its corresponding derivative (dashed line) of the B_Steel, for the heatingrate of $3{ }^{\circ} \mathrm{C} / \mathrm{min}$.

The high resolution dilatometry, which highlights precisely the two processes that take place when heating a hypoeutectoid steel, namely the pearlite dissolution into austenite $(\mathrm{P} \rightarrow \mathrm{A})$ and the allotropic transformation of ferrite into austenite $(\mathrm{F} \rightarrow \mathrm{A})$, permits the determination of the $A c_{f p}$ temperature (the pearlite dissolution finish temperature). $A c_{f p}$ is the temperature at which the first contraction on the dilatometric curve, due to pearlite to austenite transformation ( $\mathrm{P} \rightarrow \mathrm{A})$, finishes; it is also a transition temperature between the two transformations, $\mathrm{P}$ $\rightarrow \mathrm{A}$ and $\mathrm{F} \rightarrow \mathrm{A}[3,4,6,7,14-16]$. Although it is quite dificult to determine this temperature on the dilatometric 
curve, $\Delta \mathrm{L} / \mathrm{L}_{\mathrm{o}}=\mathrm{f}(\mathrm{T})$, is much easier to highlight it on the first derivative curve, $\mathrm{d}\left(\Delta \mathrm{L} / \mathrm{L}_{\mathrm{o}}\right) / \mathrm{dT}=\mathrm{f}(\mathrm{T})$, curve that has two peaks which indicates the contractions caused by $(\mathrm{P}$ $\rightarrow \mathrm{A})$ and $(\mathrm{F} \rightarrow \mathrm{A})$ transformations, (Figures 1 and 2); the temperatures $A c_{1}$ and $A c_{3}$ were chosen as points of decrease of first derivative curve below the minimum value found in the section where the derivative is approximately constant, and the $A c_{f p}$ corresponds to the point where the sloping-up part of the first derivative curve starts to bend to the right $[3,4,14,15,17,18]$. Immediately after finishing pearlitedissolution $(\mathrm{P} \rightarrow \mathrm{A})$ the allotropic transformation of ferrite in austenite $(\mathrm{F} \rightarrow$ A) begins, transformation that determine also a decrease in the specific volume (a contraction). After achieving a minimum in the variation of the relative length of the specimen, on the dilatometric curves drawn for A_Steel, at a temperature noted $T_{S C}$ in Figure 1 , there is a small contraction which is better highlighted on the first derivative curves, which have a small peak at $T_{S C}$ temperature. This modification of volume is difficult to explain, being determined, probably, either through the formation of austenite from a ferrite that remains untransformed in structure (which transforms almost instantaneously due to the change in ferrite-to-austenite transformation kinetics) [1, 4, 16], either through a diffusion of carbon from rich-carbon austenite (formed of pearlite) in less-carbon austenite (formed of ferrite) [4, 18]. The modification of volume of the specimen highlighted for A_Steel, at $T_{S C}$ temperature (Figure 1), does not appear on the dilatometric curves and their corresponding derivatives obtained for B_Steel (Figure 2). Table 2 shows, depending on the heating rate, the temperatures of the critical points in solid-state phase transformation of A_Steel and B_Steel; results were obtained through processing with NETZSCH Proteus ${ }^{\circledR}$ Software 7.1.0. of the signals of variation in the length of the specimens, provided by the dilatometer, during tests.

Table 2. Results of the dilatometric analyses.

\begin{tabular}{|c|c|c|c|c|}
\hline \multirow{2}{*}{$\begin{array}{l}\text { Heating rate } \\
\left({ }^{\circ} \mathrm{C} / \mathrm{min}\right)\end{array}$} & \multicolumn{4}{|c|}{ A_Steel } \\
\hline & $\begin{array}{l}\mathrm{Ac}_{1} \\
(\mathrm{C})\end{array}$ & $\begin{array}{l}\mathrm{Ac}_{\mathrm{fp}} \\
(\mathrm{C})\end{array}$ & $\begin{array}{l}\mathrm{Ac}_{3} \\
\left({ }^{\circ} \mathrm{C}\right)\end{array}$ & $\begin{array}{c}\left(\mathrm{Ac}_{\mathrm{fp}_{0}}-\mathrm{Ac}_{3}\right) \\
(\mathrm{C})\end{array}$ \\
\hline 1 & 723.40 & 764.70 & 898.90 & 134.20 \\
\hline 3 & 724.00 & 765.60 & 899.40 & 133.80 \\
\hline 5 & 724.90 & 767.30 & 901.10 & 133.80 \\
\hline 10 & 727.60 & 770.50 & 904.20 & 133.70 \\
\hline 30 & 737.30 & 784.20 & 908.50 & 124.30 \\
\hline \multirow{2}{*}{$\begin{array}{l}\text { Heating rate } \\
\left({ }^{\circ} \mathrm{C} / \mathrm{min}\right)\end{array}$} & \multicolumn{4}{|c|}{ B_Steel } \\
\hline & $\begin{array}{l}\mathrm{Ac}_{1} \\
\left({ }^{\circ} \mathrm{C}\right)\end{array}$ & $\begin{array}{l}\mathrm{Ac}_{\mathrm{fp}} \\
(\mathrm{C})\end{array}$ & $\begin{array}{l}\mathrm{Ac}_{3} \\
(\mathrm{C})\end{array}$ & $\begin{array}{c}\left(\mathrm{Ac}_{\mathrm{fp}_{0}}-\mathrm{Ac}_{3}\right) \\
(\mathrm{C})\end{array}$ \\
\hline 1 & 698.30 & 742.20 & 838.50 & 96.30 \\
\hline 3 & 703.80 & 747.70 & 839.70 & 92.00 \\
\hline 5 & 709.60 & 753.70 & 841.60 & 87.90 \\
\hline 10 & 716.10 & 760.90 & 844.70 & 83.80 \\
\hline 30 & 731.80 & 779.30 & 852.90 & 73.60 \\
\hline
\end{tabular}

Data in Table 2 demonstrate that when increasing the heating rate, the critical points in solid-state phase transformation $\left(A c_{l}, A c_{f p}\right.$ and $\left.A c_{3}\right)$ are moving toward higher temperatures (Figures $3 \div 5$ ). In the case of A_Steel, at low heating rates $\left(1{ }^{\circ} \mathrm{C} / \mathrm{min}\right.$ and $\left.3{ }^{\circ} \mathrm{C} / \mathrm{min}\right)$ the differences between temperatures of the same critical points are very low, less than $1{ }^{\circ} \mathrm{C}\left(0.60{ }^{\circ} \mathrm{C}\right.$ for $A c_{l}, 0.90$ ${ }^{\circ} \mathrm{C}$ for $A c_{f p}$ and $0.50{ }^{\circ} \mathrm{C}$ for $\left.A c_{3}\right)$; in the case of $\mathrm{B} \_$Steel, these differences were greater, that is $5.50^{\circ} \mathrm{C}$ (for $A c_{1}$ and $A c_{f p}$ ) and $1.20{ }^{\circ} \mathrm{C}$ (for $A c_{3}$ ). Raising the heating rate has led to an increase in the differences between the temperatures of the critical points; for example, between the temperatures obtained at heating rates of $10{ }^{\circ} \mathrm{C} / \mathrm{min}$ and $30{ }^{\circ} \mathrm{C} / \mathrm{min}$, the differences were $9.70{ }^{\circ} \mathrm{C}$ for $A c_{l}$, $13.70{ }^{\circ} \mathrm{C}$ for $A c_{f p}$ and $4.30{ }^{\circ} \mathrm{C}$ for $A c_{3}$, in the case of A_Steel, respectively $15.70{ }^{\circ} \mathrm{C}$ for $A c_{l}, 18.40{ }^{\circ} \mathrm{C}$ for $A c_{f p}$ and $8.20{ }^{\circ} \mathrm{C}$ for $A c_{3}$, in the case of B_Steel.

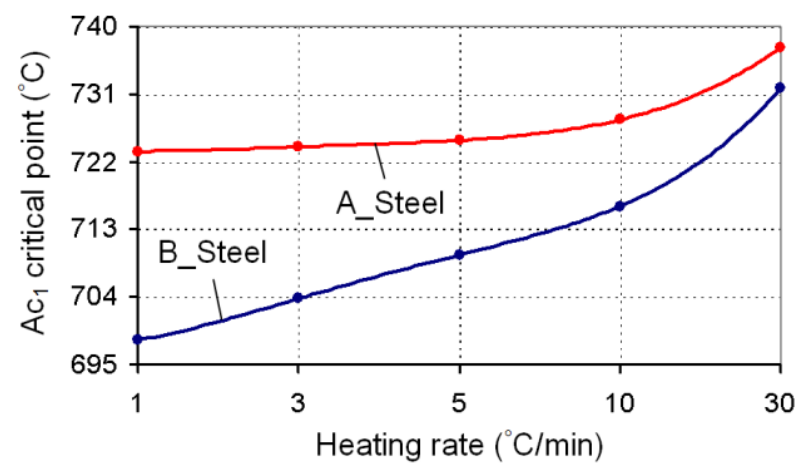

Figure 3. The influence of the heating rate on the temperature of the $A c_{l}$ critical point.

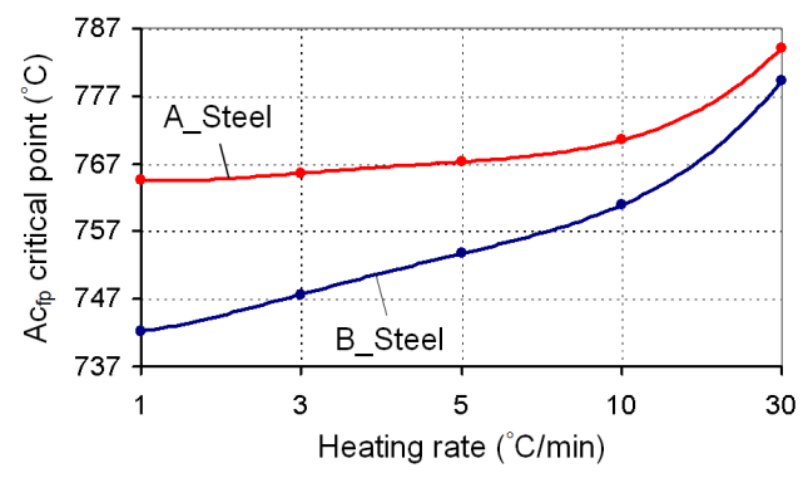

Figure 4. The influence of the heating rate on the temperature of the $A c_{f p}$ critical point.

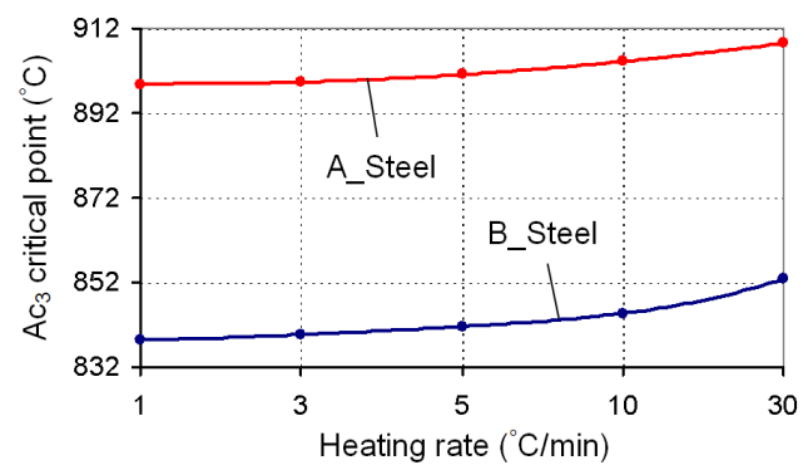

Figure 5. The influence of the heating rate on the temperature of the $A c_{3}$ critical point. 
Increasing the heating rate determined a significant displacement of the critical point $A c_{f p}$ (toward higher temperatures), the displacement of critical points $A c_{l}$, and especially the $A c_{3}$, being smaller; thus, for example, a heating rate from $1 \mathrm{C} \mathrm{C} / \mathrm{min}$ to $30 \mathrm{\circ} \mathrm{C} / \mathrm{min}$ caused a displacement with $19.50{ }^{\circ} \mathrm{C}$ for $A c_{f p}$ (from $764.70{ }^{\circ} \mathrm{C}$ to $784.20{ }^{\circ} \mathrm{C}$ ), with $13.90{ }^{\circ} \mathrm{C}$ for $A c_{1}$ (from $723.40{ }^{\circ} \mathrm{C}$ to $737.30{ }^{\circ} \mathrm{C}$ ) and with $9.60{ }^{\circ} \mathrm{C}$ for $A c_{3}$ (from $898.90{ }^{\circ} \mathrm{C}$ to $908.50{ }^{\circ} \mathrm{C}$ ), in the case of A_Steel, respectively with $37.10{ }^{\circ} \mathrm{C}$ for $A c_{f p}$ (from $742.20{ }^{\circ} \mathrm{C}$ to $779.30{ }^{\circ} \mathrm{C}$ ), with $33.50{ }^{\circ} \mathrm{C}$ for $A c_{1}$ (from $698.30{ }^{\circ} \mathrm{C}$ to $731.80{ }^{\circ} \mathrm{C}$ ) and with $14.40{ }^{\circ} \mathrm{Cfor} A c_{3}$ (from $838.50{ }^{\circ} \mathrm{C}$ to $852.90{ }^{\circ} \mathrm{C}$ ), in the case ofB_Steel. The displacements of the critical points in solid-state phase transformation with the increase of the heating rate led to the decreasing of the temperatures range $\left(A c_{f p}-A c_{3}\right)$.

In the case of A_Steel, increasing the heating rate from $1{ }^{\circ} \mathrm{C} / \mathrm{min}$ to $10{ }^{\circ} \mathrm{C} / \mathrm{min}$ caused an insignificant decrease, of less than $1{ }^{\circ} \mathrm{C}$ (from $134.20{ }^{\circ} \mathrm{C}$ for $1{ }^{\circ} \mathrm{C} / \mathrm{min}$, to $133.80{ }^{\circ} \mathrm{C}$ for $3{ }^{\circ} \mathrm{C} / \mathrm{min}$ and $5{ }^{\circ} \mathrm{C} / \mathrm{min}$ and $133.7^{\circ} \mathrm{C}$ for $10 \mathrm{C} / \mathrm{min})$; in the case of B_Steel, the decrease of the temperatures range $\left(A c_{f p}-A c_{3}\right)$ is more significant, being of $4.10 \div 4.30{ }^{\circ} \mathrm{C}$ (from $96.30{ }^{\circ} \mathrm{C}$ for $1{ }^{\circ} \mathrm{C} / \mathrm{min}$, to $92.0{ }^{\circ} \mathrm{C}$ for $3{ }^{\circ} \mathrm{C} / \mathrm{min}$, to $87.90{ }^{\circ} \mathrm{C}$ for $5{ }^{\circ} \mathrm{C} / \mathrm{min}$ and to $83.80{ }^{\circ} \mathrm{C}$ for $10 \mathrm{C} / \mathrm{min})$. Comparing the results obtained for the heating rates of $1{ }^{\circ} \mathrm{C} / \mathrm{min}$ and $30^{\circ} \mathrm{C} / \mathrm{min}$ it is noted a significant decrease of the temperatures range $\left(A c_{f p}-A c_{3}\right)$, namely, with $9.90{ }^{\circ} \mathrm{C}$ for A_Steel (from $134.20{ }^{\circ} \mathrm{C}$ to $124.30{ }^{\circ} \mathrm{C}$ ) and with $22,70{ }^{\circ} \mathrm{C}$ for B_Steel (from 96,30 ${ }^{\circ} \mathrm{C}$ to $73,60{ }^{\circ} \mathrm{C}$ ). Higher content of carbon, but especially of manganese, in the chemical composition of B_Steel $(0.093 \% \mathrm{C}$ and $1.922 \% \mathrm{Mn})$ determined, for a same heating rate, a temperatures range $\left(A c_{f p}-A c_{3}\right)$ smaller than the interval obtained for A_Steel $(0.087 \% \mathrm{C}$ and $0.511 \% \mathrm{Mn})$; in addition, in the case of B_Steel versus A_Steel, the increase in the heating rate led to higher differences between the values obtained, for both similar critical points, and temperatures range $\left(A c_{f p}-A c_{3}\right)$.

\section{Conclusions}

Dilatometric analyses performed on a DIL 402 ExpedisSUPREME dilatometer, allowed to highlight the solidstate phase transformations that occurred during the continuous heating of two hypoeutectoid steels, with $0.087 \% \mathrm{C}$ and $0.511 \% \mathrm{Mn}$, respectively with $0.093 \% \mathrm{C}$ and $1.922 \% \mathrm{Mn}$ (the dissolution of the pearlite in austenite and the allotropic transformation of proeutectoide ferrite into austenite), as well as to determine the critical temperatures (points) at which these transformations occurred. The pearlite dissolution into austenite (eutectoid transformation) was carried out in a temperature interval ranging between pearlite dissolution start temperature (critical point $A c_{l}$ ) and pearlite dissolution finish temperature (denoted $A c_{f p}$ in this article).

The temperatures of the critical points in solid-state phase transformation were influenced by the heating rate, its increase leading to the displacement of critical points to higher temperatures; raising the heating rate caused a more significant displacement of the $A c_{f p}$ point, than of the critical points $A c_{1}$ and especially $A c_{3}$.

The displacements of the critical points $A c_{f p}$ and $A c_{3}$ (with the increase of the heating rate) led to the decreasing of the temperatures range $\left(A c_{f p}-A c_{3}\right)$, range which is important for the dual-phase steels production technologies. The temperature range $\left(A c_{f p}-A c_{3}\right)$ was also influenced by the chemical composition of the steels; a higher content of carbon, but especially of manganese, determined (for a same heating rate) a decrease in this temperature range.

\section{Acknowledgement}

This work was partially supported from contract no. 18 PFE/16.10.2018 funded by Ministry of Research and Innovation within Program 1 - Development of national research and development system, Subprogram 1.2 Institutional Performance - RDI excellence funding projects, The infrastructure used for this work was partially supported from the projects "Integrated Center for research, development and innovation in Advanced Materials, Nanotechnologies, and Distributed Systems for fabrication and control (MANSiD)", Contract No. $671 / 2015$.

\section{References}

1. C. García de Andrés, F.G. Caballero, C. Capdevila, L.F. Álvarez, Mater Charact 48, 101 (2002)

2. B. Pawlowski, J Achiev Mater Manuf Eng 49, 331 (2011)

3. B. Pawlowski, J Achiev Mater Manuf Eng 54, 185 (2012)

4. C. Dulucheanu, T.L. Severin, A. Potorac, L. Irimescu, Bulgarian Chemical Communications 50 (G), 158 (2018)

5. C. García de Andrés, F.G. Caballero, C. Capdevila, Scr Mater 38(12), 1835 (1998)

6. D. San Martin, T. De Cock, A. García-Junceda, F.G. Caballero, C. Capdevila, C. García de Andrés, Materials Science and Technology 24(3), 266 (2008)

7. D. San Martin, P.E.J. Rivera-Diaz-del-Castillo, C. García de Andrés,Scr Mater 58, 926 (2008)

8. M.S. Rashid, Ann Rev Mater Sci 11, 245 (1981)

9. S.A. Golovanenko, N.M. Fonshteyn, Dual-Phase Alloyed Steels (Metallurghia, Moscow, 1986)

10. R.G. Davies, C.L. Magee, Proc. Structure and Properties of Dual-Phase Steels, 1 (The Metallurgical Society of AIME, New York, 1979)

11. G.R. Speich, Proc. Fundamentals of Dual-Phase Steels, 3 (The Metallurgical Society of AIME, New York, 1981)

12. P. Tsipouridis, Mechanical Properties of Dual-Phase Steels (Technische Universität, München, 2006)

13. A.A. Gorni, http://www.gorni.eng.br/e/Gorni_SFH THandbook.pdf, Steel forming and heat treatment handbook, Version: 20 January 2015

14. B. Pawlowski, Archives of Metallurgy and Materials 57(4), 957 (2012) 
15. F.L.G. Oliveira, M.S. Andrade, A.B. Cota, Mater Charact 58, 256 (2007)

16. F.G. Caballero, C. Capdevila, C. García de Andrés, ISIJ International 41(10), 1093 (2001)

17. P. Motyćka, M. Kövér,http://comat2012.tanger.cz/ files/proceedings/11/reports/1237.pdf, Evaluation methods of dilatometer curves of phase transformations

18. B. Pawlowski, P. Bała, J. Krawczyk,Metallurgy and Foundry Engineering 35(2), 121 (2009) 